\title{
Proteomic analysis of post mortem brain tissue from autism patients: evidence for opposite changes in prefrontal cortex and cerebellum in synaptic connectivity-related proteins
}

Jantine AC Broek', Paul C Guest ${ }^{1}$, Hassan Rahmoune ${ }^{1}$ and Sabine Bahn ${ }^{1,2^{*}}$

\begin{abstract}
Background: Autism is a neurodevelopmental disorder characterized by impaired language, communication and social skills. Although genetic studies have been carried out in this field, none of the genes identified have led to an explanation of the underlying causes. Here, we have investigated molecular alterations by proteomic profiling of post mortem brain samples from autism patients and controls. The analysis focussed on prefrontal cortex and cerebellum as previous studies have found that these two brain regions are structurally and functionally connected, and they have been implicated in autism.
\end{abstract}

Methods: Post mortem prefrontal cortex and cerebellum samples from autism patients and matched controls were analysed using selected reaction monitoring mass spectrometry (SRM-MS). The main objective was to identify significantly altered proteins and biological pathways and to compare these across these two brain regions.

Results: Targeted SRM-MS resulted in identification of altered levels of proteins related to myelination, synaptic vesicle regulation and energy metabolism. This showed decreased levels of the immature astrocyte marker vimentin in both brain regions, suggesting a decrease in astrocyte precursor cells. Also, decreased levels of proteins associated with myelination and increased synaptic and energy-related proteins were found in the prefrontal cortex, indicative of increased synaptic connectivity. Finally, opposite directional changes were found for myelination and synaptic proteins in the cerebellum.

Conclusion: These findings suggest altered structural and/or functional connectivity in the prefrontal cortex and cerebellum in autism patients, as shown by opposite effects on proteins involved in myelination and synaptic function. Further investigation of these findings could help to increase our understanding of the mechanisms underlying autism relating to brain connectivity, with the ultimate aim of facilitating novel therapeutic approaches.

Keywords: Autism, Synaptic regulation, Molecular profiling, Post mortem brain, Proteome, Selected reaction monitoring mass spectrometry

\footnotetext{
* Correspondence: sb209@cam.ac.uk

'Department of Chemical Engineering and Biotechnology, University of Cambridge, Tennis Court Road, CB2 1QT Cambridge, UK

${ }^{2}$ Department of Neuroscience, Erasmus Medical Centre, Dr. Molenwaterplein 50, 3015 GE Rotterdam, The Netherlands
} 


\section{Background}

Autism spectrum disorders (ASDs) are neurodevelopmental conditions characterized by impairments or alterations in socialisation, with language changes and restricted and/or repetitive behaviours. Recent studies have estimated the prevalence of autism at 1 in 110 with evidence for a strong gender bias. Approximately four times as many males as females are diagnosed with autism based on Diagnostic and Statistical Manual of Mental Disorders (DSM)-5 criteria. Children with autism commonly display abnormal development before the age of three years, particularly those with the regressive autism sub-type [1-3]. Despite the distressing effects that autism can have on the lives of patients and their families, the molecular basis of this condition remains largely unknown. Consequently, there are still no effective pharmacological interventions that can ameliorate the core symptoms of autism.

A number of previous studies have attempted to elucidate pathomechanisms associated with autism using imaging, genetic and transcriptomic approaches. Although results have been sparse and sometimes conflicting across studies, a consensus has emerged which suggests changes in brain connectivity and synaptic function in autism patients $[1,4]$. Specific genes which have been implicated include NLGN1 (neuroligin) and NRXN1 (neurexin) [4], and this has suggested that changes in local and distal connectivity may result from an imbalance of neuronal excitation and inhibition $[5,6]$. This may also involve dysfunction of myelination pathways, as shown by the finding of circulating antibodies against myelin basic protein (MBP) and myelin-associated glycoprotein (MAG) in some autism patients $[7,8]$.

Proteomic profiling studies have shown that brainderived neurotrophic factor (BDNF) and glial fibrillary acidic protein (GFAP) are altered in autism patients. BDNF is a growth factor which may be related to the increased brain volumes seen in some young children with autism [9]. This is consistent with the findings of imaging studies of autism subjects, which have identified aberrant white matter growth patterns [10-12]. GFAP is an astrocytic marker and astrocytes are known to be involved in synaptic connectivity and inflammation [13]. Increased astrocyte activity has been observed in ASD patients $[14,15]$ and changes in inflammatory pathways have been observed in the cerebral cortex, white matter and cerebellum [16]. Furthermore, circulating autoantibodies have been detected against GFAP and other proteins involved in neuronal and synaptic functions, including neurotrophic factors and neuronal-axonal filaments $[17,18]$. Finally, changes in mitochondrial and energy pathways have also been reported [19], although it has been hypothesized that these changes may be secondary to an as yet unidentified disease process [20]. Several independent studies have corroborated that creatine kinase (CK), an enzyme important for energy homeostasis, is one of the most robust chemical changes in autism and this is likely to parallel changes in synaptic remodelling [21].

In order to extend these studies and increase our understanding of the proteins and biological pathways affected in autism, we have carried out a targeted proteomic profiling study of post mortem brain samples from individuals with autism compared to controls, using selected reaction monitoring mass spectrometry (SRM-MS). SRM is an accurate, reproducible and quantitative technique to measure predetermined sets of proteins within the femto- to attomolar concentration range [22,23]. This method has advantages over Western blot analysis as multiple readings are taken of each analyte compared to only one for Western blot analysis [24]. Furthermore, the targeting of peptide sequences analyzed in the SRM method makes this a highly specific and quantitative analytical method whereas the Western blot approach relies on antibody reactivity and, therefore, may result in non-specificity due to potential antibody cross reactivity [25]. Our main objective was to identify changes in protein expression levels and to explore whether the affected proteins could be associated with the dysconnectivity hypothesis of autism.

\section{Methods}

\section{Subjects}

Post mortem prefrontal cortex (PFC) (Brodmann area 10; autism $n=10$, controls $n=10$ ) and cerebellum $(C B)$ (lateral posterior and anterior lobe, autism $n=16$, controls $\mathrm{n}=17$ ) were provided by the National Institute of Child Health and Human Development (NICHD) Brain and Tissue Bank for Developmental Disorders (University of Maryland School of Medicine, Baltimore, MD, USA). Patients were matched to controls with respect to age of death (PFC: $P=0.99$; CB: $P=0.80$ ), gender (PFC: $P=1.00$; CB: $P=0.70$ ), post mortem interval (PMI) (PFC: $P=0.08$; $\mathrm{CB}: P=0.18$ ) and brain $\mathrm{pH}$ (PFC: $P=0.51$; $\mathrm{CB}: P=0.66$ ), which is indicated in the additional files (see Additional file 1 for PFC and Additional file 2 for CB). The analysis of prefrontal cortex included samples from 10 autism individuals (age $=21.3 \pm 4.3$ years, $\mathrm{PMI}=22.1 \pm 3.9$ hours) and 10 matched controls (age $=21.4 \pm 4.3$ years, $\mathrm{PMI}=14.7 \pm$ 0.8 hours), and cerebellum tissue included 14 individuals with a diagnosis of autism (age $=18.6 \pm 3.4$ years, PMI $=$ $22.7 \pm 3.5$ hours) and 17 matched controls (age $=17.5 \pm$ 2.9 years, $\mathrm{PMI}=16.7 \pm 1.6$ hours) (Table 1 ). The study was approved by the Columbia University Medical School Institutional review board, consent was obtained from next of kin and all samples were de-identified and personal information anonymised. Diagnosis of autism was confirmed by the structured Autism Diagnostic Interview- 
Table 1 Demographic data for control and autism subjects

\begin{tabular}{|c|c|c|c|c|c|c|}
\hline Diagnosis & Gender & Age & PMI (hours) & Ethnicity & Medication history & Brain area \\
\hline control & male & 12 & 16 & Caucasian & NA & $C B$ \\
\hline control & male & 20 & 18 & Caucasian & NA & PFC \\
\hline control & male & 37 & 12 & African American & marijuana & $\mathrm{PFC}, \mathrm{CB}$ \\
\hline control & male & 9 & 36 & Caucasian & NA & $C B$ \\
\hline control & female & 19 & 29 & Caucasian & none & $\mathrm{CB}$ \\
\hline control & female & 20 & 9 & Caucasian & none & $C B$ \\
\hline control & male & 46 & 13 & Caucasian & NA & $\mathrm{PFC}, \mathrm{CB}$ \\
\hline control & male & 5 & 18 & African American & NA & $C B$ \\
\hline control & male & 8 & 16 & African American & NA & $\mathrm{PFC}, \mathrm{CB}$ \\
\hline control & male & 20 & 19 & Caucasian & NA & $\mathrm{CB}$ \\
\hline control & female & 4 & 15 & African American & NA & $C B$ \\
\hline control & male & 22 & 13 & African American & none & $\mathrm{PFC}, \mathrm{CB}$ \\
\hline control & female & 16 & 13 & Caucasian & NA & $\mathrm{PFC}, \mathrm{CB}$ \\
\hline control & male & 33 & 16 & Caucasian & NA & $\mathrm{PFC}, \mathrm{CB}$ \\
\hline control & male & 15 & 12 & Caucasian & NA & CB \\
\hline control & female & 16 & 11 & Caucasian & NA & $\mathrm{PFC}, \mathrm{CB}$ \\
\hline control & male & 13 & 19 & Caucasian & NA & $\mathrm{PFC}, \mathrm{CB}$ \\
\hline control & male & 3 & 16 & Hispanic & none & $\mathrm{PFC}, \mathrm{CB}$ \\
\hline autism & female & 20 & 50 & Caucasian & NA & $C B$ \\
\hline autism, MR & male & 9 & 12 & African American & Zyprexa, Reminyl & CB \\
\hline autism, S & male & 11 & 27 & Hispanic & NA & $\mathrm{PFC}, \mathrm{CB}$ \\
\hline autism & female & 4 & 13 & African American & NA & $C B$ \\
\hline autism & male & 9 & 16 & African American & NA & CB \\
\hline autism $^{a}$ & male & 7 & 20 & African American & NA & $C B$ \\
\hline autism & male & 14 & 9 & Caucasian & NA & CB \\
\hline autism, MR & male & 20 & 14 & Caucasian & Naltrexone & $\mathrm{PFC}, \mathrm{CB}$ \\
\hline autism & male & 38 & 26 & African American & Respirdal, Luvox & PFC, CB \\
\hline autism, S & male & 46 & 29 & Caucasian & NA & PFC, CB \\
\hline autism & male & 7 & 3 & Caucasian & NA & PFC \\
\hline autism & male & 22 & 18 & African American & Risperdal & PFC, CB \\
\hline autism, S & female & 16 & 13 & Caucasian & Depakote, Keppra, Vitamin B6 and Prozac & PFC, CB \\
\hline autism, MR & male & 33 & 50 & Caucasian & Seroquel, Prozac, Depakote, Geodon & $\mathrm{PFC}, \mathrm{CB}$ \\
\hline autism, S & male & 16 & 20 & Caucasian & Risperdal, Luvox, Clonidine and Insulin & PFC, CB \\
\hline autism & male & 4 & 21 & Caucasian & NA & $\mathrm{PFC}, \mathrm{CB}$ \\
\hline
\end{tabular}

$\mathrm{ID}=$ identification code, $\mathrm{PFC}=$ prefrontal cortex, $\mathrm{CB}=$ cerebellum, $\mathrm{MR}=$ mental retardation, $\mathrm{S}=$ seizure, NA = Not Applicable for control subjects and Not Available for cases. ${ }^{\text {T}}$ This sample was removed as an outlier and not considered in further statistical analyses.

Revised (ADI-R) carried out with the parents, the childhood autism rating scale (CARS), family history documentation, gene analysis to exclude genetic disorders and mutations, and neurological examination (Table 1). Subjects with a diagnosis of autism were included in the study. Local ethical approval for use of this tissue was granted by the Cambridgeshire Local Research Ethics Committee.

\section{Sample preparation}

All biochemicals and reagents were obtained from SigmaAldrich (Poole, UK) unless specified otherwise. Brain tissues (approximately $30 \mathrm{mg}$ ) were sectioned using a Leica Cryostat (Milton Keynes, UK), collected into pre-chilled lysing matrix D tubes (MP Biomedicals; Cambridge, UK) and stored at $-80^{\circ} \mathrm{C}$ until use. Protein extraction was performed by addition of fractionation buffer (7 M urea, $2 \mathrm{M}$ 
thiourea, 4\% 3-[(3-cholamidopropyl)dimethylammonio]1-propanesulfonate, 2\% ASB14 and $70 \mathrm{mM}$ dithiotreitol (DTT), followed by sonication for 10 seconds using a Branson Sonifier 150 (Thistle Scientific; Glasgow, UK) and vortexing for 30 minutes at $4^{\circ} \mathrm{C}$. The homogenates were centrifuged for 3 minutes at 17,000 $g$ and the supernatants collected for precipitation of the proteins using 4:1 volumes ice-cold acetone. The resulting pellets were suspended in $100 \mu \mathrm{L}$ of $50 \mathrm{mM} \mathrm{NH}_{4} \mathrm{HCO}_{3}$ (pH 8.0). Sulfhydryl groups on proteins were reduced by incubation with $100 \mathrm{mM}$ DTT for 30 minutes at $60^{\circ} \mathrm{C}$ and alkylated with $200 \mathrm{mM}$ iodacetamide for 30 minutes at $37^{\circ} \mathrm{C}$. Proteins were cleaved into peptides by incubation with 1:50 (trypsin:protein) porcine trypsin (Promega; Madison, WI, USA) for 17 hours at $37^{\circ} \mathrm{C}$ and stopped after 16 hours by addition of $0.80 \mu \mathrm{L}$ of $8.8 \mathrm{M} \mathrm{HCl}$. Samples were stored at $-80^{\circ} \mathrm{C}$. Prior to mass spectrometry analyses, $0.1 \%$ formic acid was added to a final concentration of $0.12 \mu \mathrm{g} / \mu \mathrm{L}$ protein.

\section{SRM-MS}

Digested prefrontal cortex and cerebellum proteomes were analysed using SRM-MS on a Xevo TQ-S mass spectrometer coupled to a nanoAcquity UPLC system (Waters Corporation, Wilmslow, UK), as described previously [23]. Protein candidates were selected for this analysis given their association with pathways which have been implicated previously in autism. Physiochemical criteria for selecting tryptic peptides were based on peptide count, uniqueness and quality of transitions. All SRM functions had a 6 minute window of the predicted retention time and scan times were 0.02 seconds. Two peptides were selected for each target protein and isotopically-labelled peptides were synthesized at JPT Peptide Technologies $\mathrm{GmbH}$ (Berlin, Germany). The samples and labelled peptides were mixed together and separated using the following 42 minutes gradient: $97 / 3 \%(\mathrm{~A} / \mathrm{B})$ to $70 / 30 \%$ in 20 minutes; $70 / 30 \%$ to $15 / 85 \%$ in 5 minutes; and in 3 minutes to $97 / 3 \%$. Peptide spectra were acquired in SRM mode using a capillary voltage of $2.35 \mathrm{kV}$ and a cone voltage of $33 \mathrm{~V}$. At least three transitions were measured for each peptide. The candidate proteins were identified with the SRM method as described previously [23].

\section{Statistical analyses}

Statistical analyses of SRM data were conducted in the R statistical programming language (version 2.15.3; www.rproject.org), using the package MSstats [26-28]. Data processing consisted of $\log _{2}$ transformation to stabilize the variance and normalize peak intensities. The data were then analysed using a linear mixed model to detect proteins or peptides that were present at significantly different levels in cases compared to controls (autism/control). In the model, the experimental characteristics were linked to the data in terms of biological condition, labelling state, technical and biological replication and potentially interfering transitions [28]. The scope of inference for both biological replicates and technical replicates were set to 'restricted', as conclusions about the data are confined to the study itself. Furthermore, additional model interactions were performed for interference transitions. These analyses resulted in $P$-values, $Q$-values (allowing for multiple testing) and ratio changes (autism/control).

\section{Results}

\section{Sample quality}

SRM-MS analysis of prefrontal cortex protein extracts from autism and control patients showed no batch effects as indicated by principal component analysis (PCA), of which an additional plot shows this in more detail (Additional file 3). Conversely, analysis of the cerebellum protein extracts led to the identification of one outlying sample. After removal of this sample, no further outliers were detected, as is visualised in the additional PCA plot (Additional file 4). All further statistical analyses were carried out using only the remaining samples.

\section{SRM-MS detection}

SRM-MS was used for targeted analysis of proteins associated with energy metabolism, astrocyte function, myelination and synaptic vesicles in accordance with literature evidence [4-21]. The proteins which were detectable using SRM-MS analysis are indicated in Table 2. GFAP, vimentin (VIME), creatine kinase B-type (CKB), MAG, MBP, myelinoligodendrocyte glycoprotein (MOG), myelin proteolipid protein (PLP1), dynamin-2 (DNM2), syntaxin-1A (STX1A), syntaxin-binding protein 1 (STXBP1), synapsin-2 (SYN2), synaptotagmin-1 (SYT1), protein kinase C casein kinase substrate 1 (PACSIN1) were detected in both prefrontal cortex and cerebellum from all patients and controls. However, reelin (RLN) was only identified in the cerebellum and was therefore not used in the comparative analysis.

\section{Comparative SRM-MS analysis of proteins in prefrontal cortex and cerebellum}

Prefrontal cortex and cerebellum showed a similar decrease in the levels of the immature astrocyte marker VIME, whereas the mature astrocyte marker GFAP was increased and this occurred only in the cerebellum (Figure 1). The energy-related CKB was increased by more than $70 \%$ in the prefrontal cortex and showed a non-significant decrease $(P=0.2605)$ in the cerebellum. The myelin-related proteins MAG and PLP1 were decreased in the prefrontal cortex with a concomitant increase in the synaptic proteins SYN2 and STBP1, although the latter was not significant $(P=$ 0.1002). Conversely, the myelin related proteins MAG, MBP, MOG and PLP1 were all increased by more than 30\% and the synaptic proteins STX1, SYT1 and PACSIN1 were 
Table 2 SRM-MS testing of targeted candidate proteins in post mortem prefrontal cortex and cerebellum from autism patients compared to matched controls

\begin{tabular}{|c|c|c|c|c|c|c|c|c|}
\hline \multirow[b]{2}{*}{ Pathways } & \multirow[b]{2}{*}{ Gene } & \multirow[b]{2}{*}{ Protein name } & \multirow{2}{*}{$\begin{array}{c}\text { Prefrontal } \\
\text { cortex } \\
\text { ratio }\end{array}$} & \multirow{2}{*}{$\begin{array}{l}\text { Cerebellum } \\
P \text {-value }\end{array}$} & \multirow[b]{2}{*}{ Pathways } & \multirow[b]{2}{*}{ Gene } & \multirow[b]{2}{*}{$\begin{array}{c}\text { Protein } \\
\text { name }\end{array}$} & \multirow{2}{*}{$\begin{array}{c}\text { Prefrontal } \\
\text { cortex } \\
\text { ratio }\end{array}$} \\
\hline & & & & & & & & \\
\hline Cell adhesion & RELN & Reelin & ND & ND & Cell adhesion & RELN & Reelin & ND \\
\hline \multirow[t]{2}{*}{ Astrocyte } & GFAP & Glial fibrillary acidic protein & 1.02 & 0.7399 & 0.7968 & 1.14 & $1.8 \mathrm{E}-05^{\mathrm{a}}$ & $7.42 \mathrm{E}-5$ \\
\hline & VIME & Vimentin & 0.69 & $2.8 \mathrm{E}-5^{\mathrm{a}}$ & 0.0002 & 0.56 & $1<\mathrm{E}-10^{\mathrm{a}}$ & $1<\mathrm{E}-9$ \\
\hline Energy & $C K B$ & Creatine kinase B-type & 1.73 & $1.3 \mathrm{E}-9^{\mathrm{a}}$ & $1.82 \mathrm{E}-8$ & 0.92 & 0.2605 & 0.3777 \\
\hline \multirow[t]{4}{*}{ Myelin } & MAG & Myelin-associated glycoprotein & 0.76 & $0.0087^{\mathrm{a}}$ & 0.0272 & 1.30 & $0.0016^{\mathrm{a}}$ & 0.0042 \\
\hline & $M B P$ & Myelin basic protein & 0.85 & 0.1440 & 0.2373 & 1.41 & $0.0003^{\mathrm{a}}$ & 0.0009 \\
\hline & MOG & Myelin-oligodendrocyte glycoprotein & 0.81 & 0.0567 & 0.1222 & 1.37 & $0.0002^{\mathrm{a}}$ & 0.0006 \\
\hline & $P L P 1$ & Myelin proteolipid protein & 0.82 & $0.0143^{\mathrm{a}}$ & 0.0400 & 1.37 & $2.8 \mathrm{E}-10^{\mathrm{a}}$ & $2.69 \mathrm{E}-9$ \\
\hline \multirow[t]{6}{*}{ Synaptic vesicle } & DNM2 & Dynamin-2 & 1.05 & 0.7811 & 0.8024 & 0.87 & 0.2910 & 0.4018 \\
\hline & STXIA & Syntaxin-1A & 1.07 & 0.2086 & 0.3165 & 0.88 & $0.0102^{\mathrm{a}}$ & 0.0227 \\
\hline & STXBP1 & Syntaxin-binding protein 1 & 1.28 & 0.1002 & 0.1753 & 0.97 & 0.8031 & 0.8626 \\
\hline & SYN2 & Synapsin-2 & 1.29 & $0.0486^{\mathrm{a}}$ & 0.1135 & 1.04 & 0.6499 & 0.7539 \\
\hline & SYT1 & Synaptotagmin-1 & 1.06 & 0.4092 & 0.5456 & 0.87 & $0.0165^{\mathrm{a}}$ & 0.0342 \\
\hline & PACSIN1 & Protein kinase $C$ casein kinase substrate 1 & 0.96 & 0.4540 & 0.5778 & 0.84 & $8.1 \mathrm{E}-5^{\mathrm{a}}$ & 0.0003 \\
\hline
\end{tabular}

ND = not detected; ${ }^{\text {a }}$ significant $P$-value.

Indicated are the themes, protein name, the ratio (autism/control), the $P$-value and the $Q$-value. Grey shading indicates the proteins with a significant $P$-value or $Q$-value and a ratio of $>10 \%$.

decreased in the cerebellum. DNM2 was also decreased in the cerebellum although this was not significant $(P=$ 0.2910).

\section{Discussion}

This is the first report presenting results from a proteomics mass spectrometry study of rare post mortem brain tissues from autism patients and controls. Prefrontal cortex and cerebellum proteomes were investigated because a number of studies have already shown that these brain regions are affected in autism [29-32]. It has previously been suggested that impaired prefrontal cortex-cerebellar circuitry may be linked to autism symptoms [33]. In addition to its well known role in regulation of motor functions, it is now established that the cerebellum is also involved in regulation of cognition and other higher brain functions. Structural studies in non-human primates have shown that the cerebellum receives inputs through afferent

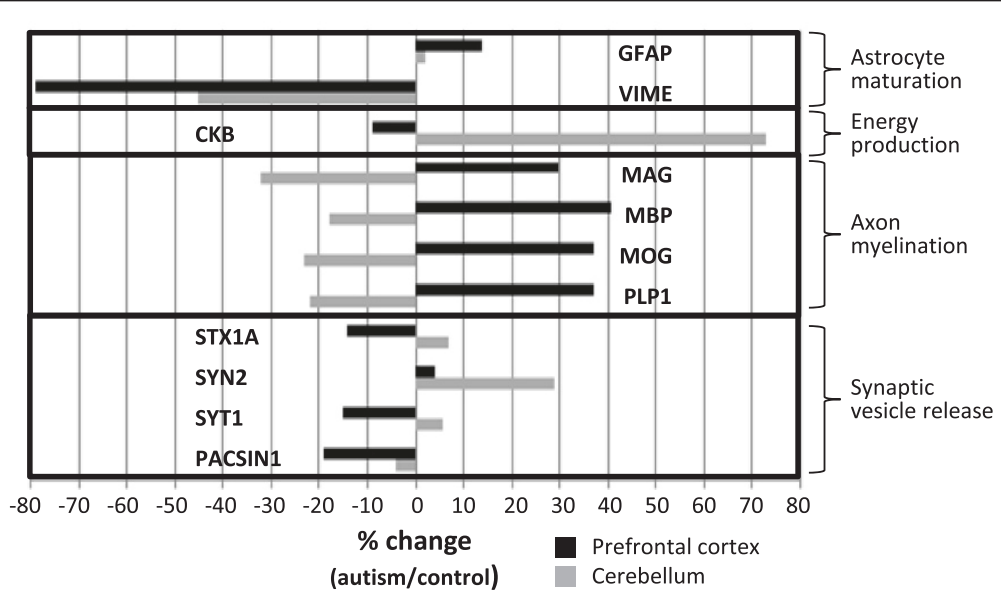

Figure 1 Histogram showing selected reaction monitoring mass spectrometry (SRM-MS) analysis of proteins involved in astrocyte maturation, energy production, axon myelination and synaptic vesicle release. The percent changes of each protein are shown for post mortem prefrontal cortex (black) and cerebellum (grey) tissues from autism patients compared to matched controls. The protein codes are defined in Table 2. 
nerves from several brain areas such as the prefrontal cortex which are known for their role in cognition and mood regulation [34-36]. Likewise, efferent nerves from the cerebellum have been traced to both motor and nonmotor areas of the frontal cortex $[37,38]$, which are routed through thalamic nuclei and complete the circuit [38]. Furthermore, functional evidence for a role of the cerebellum in higher brain function has been demonstrated by magnetic resonance imaging (MRI), which showed that activity in the cerebellar dentate nucleus correlated with changes in activity in the limbic system, parietal lobes and prefrontal cortex [39].

The main findings of this study provide evidence that molecular processes are differentially dysregulated in different brain regions in autism, which could affect various higher functions such as cognition, working memory, mood and emotions [40-42]. Here, the SRM-MS results showed decreased levels of proteins associated with myelination and increased levels of synaptic proteins in the prefrontal cortex, with opposite directional changes of the same proteins in the cerebellum. This is consistent with our unpublished observations showing decreased levels of myelin proteins in post mortem prefrontal cortex tissue in other psychiatric disorders, such as schizophrenia, bipolar and major depressive disorder. Furthermore, dysregulation of synaptic proteins may reflect alterations in synaptic density and a comparison with published data confirms the alterations of STX1A, STXBP1 and SYN2 in autism at the mRNA level [43]. In addition, SRM-MS showed an approximate $70 \%$ increase in the levels of CKB in the prefrontal cortex with a small non-significant decrease of this protein in the cerebellum. CKB has been used as an indicator of functional activation in magnetic resonance spectroscopy studies of the brain [44]. Increased myelination has an important role in promoting and maintaining axon integrity by increasing axonal calibre and thereby preventing sprouting and synaptic plasticity [45]. Moreover, decreased myelin thickness has previously been associated with disconnection of long-distance pathways, neighbouring connectivity and disruption of pathways involved in emotions [46]. Therefore, the current findings could suggest differential regulation of local synaptic connectivity in the prefrontal cortex and the cerebellum of autism patients.

It is possible that changes in local connectivity impair the transfer of information across different brain regions, given that the higher brain functions mentioned above require co-activation of networked brain areas [31]. Activation is known to be coordinated based on interregional relaying of signals through the connecting white matter tracts [47] and previous studies in autism have found changes in connectivity and overgrowth of brain tissues [40], along with alterations of white matter
$[6,48]$. However, studies have shown that the patterns of white matter aberrations tend to differ depending on brain area, age and research techniques $[6,40,48]$. Therefore it is interesting that the present findings identified a difference in myelination-related protein levels in the prefrontal cortex and cerebellum. As white matter is mainly comprised of glial cells and myelinated axons, the current changes in myelin-related proteins may be associated with the proposed disconnectivity in autism. Likewise, we also identified decreased levels of the immature glial cell marker VIME in both brain regions and increased levels of GFAP in the cerebellum. This may be indicative of a relative loss of astrocyte precursor cells in the cerebellum of autism patients.

Cerebellar damage can result in verbal and communication deficits, as well as a reduction of higher-order executive functions and other cognitive abilities such as language processing, visuospatial abilities and attention [49]. Dysfunction of these pathways could be due to loss of cerebellar Purkinje cells, which has been observed in post mortem brains from autism patients compared to controls. Interestingly, this does not appear to be related to seizure activity as patients both with and without comorbid epilepsy showed Purkinje cell loss [50,51].

One limitation of the present investigation was the low statistical power for detection of proteomic changes. This resulted from the limited number of post mortem samples available and the relatively wide age ranges of the subjects. However, the low numbers could not be avoided due to the scarcity of such high quality samples in brain banks. Moreover, the number of samples from female subjects is low due to the lower female prevalence [52]. Also, the different age groups studied could result in a masking of some molecular changes since previous studies have shown age dependent changes in the levels of many serum proteins in children and adolescents with autism [53]. Due to the rarity of these samples, the subjects were matched only for gender and age but not for drug treatment. Therefore, we cannot rule out the possibility that some of the changes may be medication or drug effects. Therefore, the presented findings should be considered preliminary and further validation studies should be carried out using larger sample sets, once these become available. This will require increased bio-banking efforts to allow studies involving stratification of samples by age and gender.

\section{Conclusion}

The findings from our proteomics study suggest brain region-specific changes in local connectivity in the prefrontal cortex and cerebellum in autism patients as shown by opposite regulation of proteins involved in myelination and synaptic regulation. These effects appeared to be associated with differential effects on glial 
cell function, energy metabolism and synaptic vesicle release across the two brain regions. Further molecular profiling and imaging studies on a larger brain sample set is required to increase our understanding of the molecular pathologies of autism and for validation of the current findings. Once more brain samples are available, it will be particularly important to undertake studies on a larger sample set to investigate gender and age-related changes in autism. Such more detailed and refined investigations should lead to further insights into the pathways affected in autism with the aim to increase our understanding of this debilitating disorder and facilitate the development of novel therapeutic approaches.

\section{Additional files}

\section{Additional file 1: Demographic information for cohort of which the prefrontal cortex was analyzed.}

Additional file 2: Demographic information for cohort of which the cerebellum was analyzed.

Additional file 3: Principal component analysis (PCA) plots of SRM-MS data obtained from prefrontal cortex. In the PCA plots, every run is represented as a data point and all triplicates of the same run have the same colour. Samples of both controls and patients are visualised. No segregation of samples was identified, indicating that a batch effect was not present. The accompanying text with the data points is not similar to the sample code depicted in Table 1

Additional file 4: Principal component analysis (PCA) plots of SRM-MS data obtained from the cerebellum. In the PCA plots, every run is represented as a data point and all triplicates of the same run have the same colour. Samples of both controls and patients are visualised. After removal of one outlier, the PCA plot showed no segregation of samples, indicating that a batch effect was not present. The accompanying text with the data points is not similar to the sample code depicted in Table 1.

\section{Abbreviations}

ADI-R: Autism Diagnostic Interview-Revised; ASD: autism spectrum disorder; BBB: blood-brain barrier; BDNF: brain-derived neurotrophic factor;

CARS: Childhood Autism Rating Scale; CB: cerebellum; CKB: creatine kinase B; DSM-IV: Diagnostic and Statistical Manual of Mental Disorders, fourth edition; DTT: dithiotreitol; DNM2: dynamin-2; GFAP: glial fibrillary acidic protein; LC-MSE: liquid chromatography mass spectrometry; MAG: myelin-associated glycoprotein; MBP: myelin basic protein; MOG: myelin oligodendrocyte glycoprotein; MRI: magnetic resonance imaging; NICHD: National Institute of Child Health and Human Development; NLGN1: neuroligin; NRXL1: neurexin; PACSIN1: protein kinase $C$ casein kinase substrate 1; PCA: principal component analysis; PFC: prefrontal cortex; PLP1: myelin proteolipid protein PMI: post mortem interval; QC: quality control; Q-TOF: Quadrupole time-offlight; RLN: reelin; SRM-MS: selected reaction monitoring mass spectrometry; STBXP1: syntaxin-binding protein 1; SYN2: synapsin-2; STX1A: syntaxin-1A; SYT1: synaptotagmin-1.

\section{Competing interests}

$\mathrm{SB}$ is a consultant for Myriad-RBM/Psynova Neurotech Ltd. The other authors declare no competing interests.

\section{Authors' contributions}

JACB carried out the molecular profiling data analyses, interpreted the results, prepared the figures and tables, and wrote the manuscript. HR and PCG interpreted the results and contributing to writing and editing of the manuscript. SB conceived the study, interpreted the results and edited the manuscript. All authors read and approved the manuscript.

\section{Acknowledgements}

This work was funded by Autism Speaks Grant \#6009 and the Dutch Fund for Economic Structure Reinforcement (FES) under grant agreement number 0908 (NeuroBasic PharmaPhenomics project).

All samples were obtained from the National Institute of Child Health and Human Development (NICHD) Brain and Tissue Bank for Developmental Disorders (University of Maryland School of Medicine, Baltimore, MD, USA) Approvals were granted by the Columbia University Medical School Institutional review board, consent was obtained from next of kin and all samples were de-identified and personal information anonymised. Written informed consent was obtained from the next of kin for publication of the participants' individual details and accompanying images in this manuscript. The consent form is held by the authors' institution/in the patients' clinical notes and is available for review by the Editor-in-Chief. Local ethical approval for use of this tissue was granted by the Cambridgeshire Local Research Ethics Committee.

Received: 1 April 2014 Accepted: 27 June 2014

Published: 30 July 2014

\section{References}

1. Lord C, Cook EH, Leventhal BL, Amaral DG: Autism spectrum disorders. Neuron 2000, 28:355-363.

2. Goldberg WA, Osann K, Filipek PA, Laulhere T, Jarvis K, Modahl C, Flodman $P$, Spence MA: Language and other regression: assessment and timing. J Autism Dev Disord 2003, 33:607-616.

3. Ozonoff S, Williams BJ, Landa R: Parental report of the early development of children with regressive autism: the delays-plus-regression phenotype. Autism 2005, 9:461-486.

4. Sudhof TC: Neuroligins and neurexins link synaptic function to cognitive disease. Nature 2008, 455:903-911.

5. Sporns $\mathrm{O}$, Tononi G, Edelman GM: Theoretical neuroanatomy: relating anatomical and functional connectivity in graphs and cortical connection matrices. Cereb Cortex 2000, 10:127-141.

6. Zikopoulos B, Barbas H: Altered neural connectivity in excitatory and inhibitory cortical circuits in autism. Front Hum Neurosci 2013, 7:609.

7. Singh VK, Warren RP, Odell JD, Warren WL, Cole P: Antibodies to myelin basic protein in children with autistic behavior. Brain Behav Immun 1993, 7:97-103.

8. Mostafa GA, El-Sayed ZA, El-Aziz MM, El-Sayed MF: Serum anti-myelinassociated glycoprotein antibodies in Egyptian autistic children. $J$ Child Neurol 2008, 23:1413-1418

9. Redcay E, Courchesne E: When is the brain enlarged in autism? A metaanalysis of all brain size reports. Biol Psychiatry 2005, 58:1-9.

10. Courchesne E, Karns CM, Davis HR, Ziccardi R, Carper RA, Tique ZD, Chisum HJ, Moses P, Pierce K, Lord C, Lincoln AJ, Pizzo S, Schreibman L, Haas RH, Akshoomoff NA, Courchesne RY: Unusual brain growth patterns in early life in patients with autistic disorder: an MRI study. Neurology 2001, 57:245-254

11. Sparks BF, Friedman SD, Shaw DW, Aylward EH, Echelard D, Artru AA, Maravilla KR, Giedd JN, Munson J, Dawson G, Dager SR: Brain structural abnormalities in young children with autism spectrum disorder. Neurology 2002, 59:184-192.

12. Herbert MR, Ziegler DA, Makris N, Filipek PA, Kemper TL, Normandin J, Sanders HA, Kennedy DN, Caviness VS Jr: Localization of white matter volume increase in autism and developmental language disorder. Ann Neurol 2004, 55:530-540.

13. Farina C, Aloisi F, Meinl E: Astrocytes are active players in cerebral innate immunity. Trends Immunol 2007, 28:138-145.

14. Stubbs G: Interferonemia and autism. J Autism Dev Disord 1995, 25:71-73.

15. Sweeten TL, Posey DJ, Shankar S, McDougle CJ: High nitric oxide production in autistic disorder: a possible role for interferon-gamma. Biol Psychiatry 2004, 55:434-437.

16. Vargas DL, Nascimbene C, Krishnan C, Zimmerman AW, Pardo CA: Neuroglial activation and neuroinflammation in the brain of patients with autism. Ann Neurol 2005, 57:67-81.

17. Kozlovskaia GV, Kliushnik TP, Goriunova AV, Turkova IL, Kalinina MA: Sergienko NS: [Nerve growth factor auto-antibodies in children with various forms of mental dysontogenesis and in schizophrenia high risk group]. Zh Nevrol Psikhiatr Im S S Korsakova 2000, 100:50-52. 
18. Connolly AM, Chez M, Streif EM, Keeling RM, Golumbek PT, Kwon JM, Riviello JJ, Robinson RG, Neuman RJ, Deuel RM: Brain-derived neurotrophic factor and autoantibodies to neural antigens in sera of children with autistic spectrum disorders, Landau-Kleffner syndrome, and epilepsy. Biol Psychiatry 2006, 59:354-363.

19. Geier DA, Kern JK, Geier MR: A prospective study of oxidative stress biomarkers in autistic disorders. Electron J Appl Psychol 2009, 5:2-10.

20. Palmieri $L$, Persico AM: Mitochondrial dysfunction in autism spectrum disorders: cause or effect? Biochim Biophys Acta 2010, 1797:1130-1137.

21. Broek JA, Brombacher E, Stelzhammer V, Guest PC, Rahmoune H, Bahn S: The need for a comprehensive molecular characterization of autism spectrum disorders. Int J Neuropsychopharmacol 2014, 17:651-673.

22. Stahl-Zeng J, Lange V, Ossola R, Eckhardt K, Krek W, Aebersold R, Domon B: High sensitivity detection of plasma proteins by multiple reaction monitoring of N-glycosites. Mol Cell Proteomics 2007, 6:1809-1817.

23. Martins-de-Souza D, Alsaif M, Ernst A, Harris LW, Aerts N, Lenaerts I, Peeters PJ, Amess B, Rahmoune H, Bahn S, Guest PC: The application of selective reaction monitoring confirms dysregulation of glycolysis in a preclinical model of schizophrenia. BMC Res Notes 2012, 5:146.

24. Picotti $P$, Aebersold R: Selected reaction monitoring-based proteomics: workflows, potential, pitfalls and future directions. Nat Methods 2012, 9:555-566.

25. Aebersold R, Burlingame AL, Bradshaw RA: Western blots versus selected reaction monitoring assays: time to turn the tables? Mol Cell Proteomics 2013, 12:2381-2382.

26. Griffin NM, Yu J, Long F, Oh P, Shore S, Li Y, Koziol JA, Schnitzer JE: Labelfree, normalized quantification of complex mass spectrometry data for proteomic analysis. Nat Biotechnol 2010, 28:83-89.

27. Clough T, Thaminy S, Ragg S, Aebersold R, Vitek O, Clough T, Thaminy S, Ragg S, Aebersold R, Vitek O: Statistical protein quantification and significance analysis in label-free LC-MS experiments with complex designs. BMC Bioinformatics 2012, 13(16):S6

28. Surinova S, Huttenhain R, Chang CY, Espona L, Vitek O, Aebersold R: Automated selected reaction monitoring data analysis workflow for large-scale targeted proteomic studies. Nat Protoc 2013, 8:1602-1619.

29. Hill EL: Executive dysfunction in autism. Trends Cogn Sci 2004, 8:26-32.

30. Fatemi SH, Aldinger KA, Ashwood P, Bauman ML, Blaha CD, Blatt GJ, Chauhan A, Chauhan V, Dager SR, Dickson PE, Estes AM, Goldowitz D, Heck DH, Kemper TL, King BH, Martin LA, Millen KJ, Mittleman G, Mosconi MW, Persico AM, Sweeney JA, Webb SJ, Welsh JP: Consensus paper: pathological role of the cerebellum in autism. Cerebellum 2012, 11:777-807

31. Just MA, Keller TA, Malave VL, Kana RK, Varma S: Autism as a neural systems disorder: a theory of frontal-posterior underconnectivity. Neurosci Biobehav Rev 2012, 36:1292-1313.

32. Watanabe $\mathrm{T}$, Yahata N, Abe O, Kuwabara H, Inoue H, Takano Y, Iwashiro N, Natsubori T, Aoki Y, Takao H, Sasaki H, Gonoi W, Murakami M, Katsura M, Kunimatsu A, Kawakubo Y, Matsuzaki H, Tsuchiya KJ, Kato N, Kano Y, Miyashita $Y$, Kasai K, Yamasue H: Diminished medial prefrontal activity behind autistic social judgments of incongruent information. PLOS One 2012, 7:e39561.

33. Rogers TD, McKimm E, Dickson PE, Goldowitz D, Blaha CD, Mittleman G: Is autism a disease of the cerebellum? An integration of clinical and pre-clinical research. Front Syst Neurosci 2013, 7:15.

34. Leichnetz GR, Smith DJ, Spencer RF: Cortical projections to the paramedian tegmental and basilar pons in the monkey. J Comp Neurol 1984, 228:388-408.

35. Brodal P: The corticopontine projection in the rhesus monkey: origin and principles of organization. Brain 1978, 101:251-283.

36. Schmahmann JD, Pandya DN: Anatomic organization of the basilar pontine projections from prefrontal cortices in rhesus monkey. J Neurosci 1997, 17:438-458.

37. Middleton FA, Strick PL: Anatomical evidence for cerebellar and basal ganglia involvement in higher cognitive function. Science 1994, 266:458-461.

38. Middleton FA, Strick PL: Cerebellar projections to the prefrontal cortex of the primate. J Neurosci 2001, 21:700-712.

39. Allen G, McColl R, Barnard H, Ringe WK, Fleckenstein J, Cullum CM: Magnetic resonance imaging of cerebellar-prefrontal and cerebellarparietal functional connectivity. Neuroimage 2005, 28:39-48.
40. Courchesne E, Pierce K, Schumann CM, Redcay E, Buckwalter JA, Kennedy DP, Morgan J: Mapping early brain development in autism. Neuron 2007, 56:399-413

41. Maximo JO, Cadena EJ, Kana RK: The implications of brain connectivity in the neuropsychology of autism. Neuropsychol Rev 2014, 24:16-31.

42. Verly M, Verhoeven J, Zink I, Mantini D, Peeters R, Deprez S, Emsell L, Boets B, Noens I, Steyaert J, Lagae L, De Cock P, Rommel N, Sunaert S: Altered functional connectivity of the language network in ASD: role of classical language areas and cerebellum. Neuroimage Clin 2014, 4:374-382.

43. Basu SN, Kollu R, Banerjee-Basu S: AutDB: a gene reference resource for autism research. Nucleic Acids Res 2009, 37:D832-D836.

44. Hyder F: Dynamic imaging of brain function. Methods Mol Biol 2009, 489:3-21.

45. Brady ST, Witt AS, Kirkpatrick LL, De Waegh SM, Readhead C, Tu PH, Lee VM: Formation of compact myelin is required for maturation of the axonal cytoskeleton. J Neurosci 1999, 19:7278-7288.

46. Zikopoulos B, Barbas $\mathrm{H}$ : Changes in prefrontal axons may disrupt the network in autism. J Neurosci 2010, 30:14595-14609.

47. Fields RD: White matter in learning, cognition and psychiatric disorders. Trends Neurosci 2008, 31:361-370.

48. Muller RA, Shih P, Keehn B, Deyoe JR, Leyden KM, Shukla DK: Underconnected, but how? A survey of functional connectivity MRI studies in autism spectrum disorders. Cereb Cortex 2011, 21:2233-2243.

49. Leggio MG, Chiricozzi FR, Clausi S, Tedesco AM, Molinari M: The neuropsychological profile of cerebellar damage: the sequencing hypothesis. Cortex 2011, 47:137-144.

50. Williams RS, Hauser SL, Purpura DP, DeLong GR, Swisher CN: Autism and mental retardation: neuropathologic studies performed in four retarded persons with autistic behavior. Arch Neurol 1980, 37:749-753.

51. Ritvo ER, Freeman BJ, Scheibel AB, Duong T, Robinson H, Guthrie D, Ritvo A: Lower Purkinje cell counts in the cerebella of four autistic subjects: initial findings of the UCLA-NSAC Autopsy Research Report. Am J Psychiatry 1986, 143:862-866.

52. Stacy ME, Zablotsky B, Yarger HA, Zimmerman A, Makia B, Lee LC: Sex differences in co-occurring conditions of children with autism spectrum disorders. Autism 2013, [Epub ahead of print].

53. Ramsey JM, Guest PC, Broek JA, Glennon JC, Rommelse N, Franke B, Rahmoune H, Buitelaar JK, Bahn S: Identification of an age-dependent biomarker signature in children and adolescents with autism spectrum disorders. Mol Autism 2013, 4:27.

doi:10.1186/2040-2392-5-41

Cite this article as: Broek et al:: Proteomic analysis of post mortem brain tissue from autism patients: evidence for opposite changes in prefrontal cortex and cerebellum in synaptic connectivity-related proteins. Molecular Autism 2014 5:41.

\section{Submit your next manuscript to BioMed Central and take full advantage of:}

- Convenient online submission

- Thorough peer review

- No space constraints or color figure charges

- Immediate publication on acceptance

- Inclusion in PubMed, CAS, Scopus and Google Scholar

- Research which is freely available for redistribution 